\title{
Abnormal alterations in the $\mathrm{Ca}^{2+} / \mathrm{CaV1.2} / \mathrm{calmodulin} / \mathrm{caMKII}$ signaling pathway in a tremor rat model and in cultured hippocampal neurons exposed to $\mathbf{M g}^{2+}$-free solution
}

\author{
XINTONG LV ${ }^{1}$, FENG GUO ${ }^{1}$, XIAOXUE XU ${ }^{2}$, ZAIXING CHEN ${ }^{1}$, XUEFEI SUN ${ }^{1}$, DONGYU MIN ${ }^{1}$, \\ YONGGANG CAO ${ }^{1}$, XIANBAO SHI $^{1}$, LEI WANG $^{3}$, TIANBAO CHEN ${ }^{3}$, CHRIS SHAW $^{3}$, \\ HUILING GAO $^{4}$, LIYING $\mathrm{HAO}^{1}$ and JIQUN CAI ${ }^{1}$
}

\begin{abstract}
${ }^{1}$ Department of Pharmaceutical Toxicology, School of Pharmacy, China Medical University; ${ }^{2}$ Department of Neurology, The First Hospital of China Medical University, Shenyang, Liaoning 110001, P.R. China; ${ }^{3}$ Molecular Therapeutics Research Group, School of Pharmacy, Queen's University, Belfast BT7 1NN, United Kingdom; ${ }^{4}$ College of Life and Health Sciences, Northeastern University, Shenyang, Liaoning 110001, P.R. China
\end{abstract}

Received October 30, 2014; Accepted July 21, 2015

DOI: $10.3892 / \mathrm{mmr} .2015 .4227$

\begin{abstract}
Voltage-dependent calcium channels (VDCCs) are key elements in epileptogenesis. There are several binding-sites linked to calmodulin (CaM) and several potential CaM-dependent protein kinase II (CaMKII)-mediated phosphorylation sites in CaV1.2. The tremor rat model (TRM) exhibits absence-like seizures from 8 weeks of age. The present study was performed to detect changes in the $\mathrm{Ca}^{2+} / \mathrm{CaV} 1.2 / \mathrm{CaM} / \mathrm{CaMKII}$ pathway in TRMs and in cultured hippocampal neurons exposed to $\mathrm{Mg}^{2+}$-free solution. The expression levels of $\mathrm{CaV1.2}, \mathrm{CaM}$ and phosphorylated CaMKII (p-CaMKII; Thr-286) in these two models were examined using immunofluorescence and western blotting. Compared with Wistar rats, the expression levels of CaV1.2 and $\mathrm{CaM}$ were increased, and the expression of $\mathrm{p}$-CaMKII was decreased in the TRM hippocampus. However, the expression of the targeted proteins was reversed in the TRM temporal cortex. A significant increase in the expression of $\mathrm{CaM}$ and decrease in the expression of CaV1.2 were observed in the TRM cerebellum. In the cultured neuron model, p-CaMKII and CaV1.2 were markedly decreased. In addition, neurons exhibiting co-localized expression of $\mathrm{CaV} 1.2$ and $\mathrm{CaM}$ immunoreactivities were detected. Furthermore, intracellular calcium concentrations were increased in these two models. For the first time, o the best of our knowledge, the data of the present study suggested that abnormal alterations
\end{abstract}

Correspondence to: Professor Jiqun Cai, Department of Pharmaceutical Toxicology, School of Pharmacy, China Medical University, 92 Two North Road, Shenyang, Liaoning 110001, P.R. China

E-mail: jiquncai@126.com

Key words: voltage-dependent calcium channels, calmodulin, calmodulin-dependent protein in the $\mathrm{Ca}^{2+} / \mathrm{CaV} 1.2 / \mathrm{CaM} / \mathrm{CaMKII}$ pathway may be involved in epileptogenesis and in the phenotypes of TRMs and cultured hippocampal neurons exposed to $\mathrm{Mg}^{2+}$-free solution.

\section{Introduction}

Epilepsy is one of the most common neurological conditions and is a set of chronic brain diseases caused by abnormal discharge of neurons within a brief time-frame (1). Voltage-dependent calcium channels (VDCCs) have important effects on neurotransmitter release and membrane excitability $(2,3)$. $\mathrm{CaV} 1.2$ is the most predominant VDCC located in certain dendrites of hippocampal and cortical neurons (4-6). Previous studies have demonstrated that abnormal expression of CaV1.2 is present in different epilepsy phenotypes (7-9). At early stages during and following pilocarpine-induced status epilepticus, significant changes of $\mathrm{CaV} 1.2$ have been found in different groups of hippocampal neurons (7). However, no changes were observed in the protein expression of $\mathrm{CaV} 1.2$ in inferior colliculus neurons of genetically epilepsy-prone rats, compared with control Sprague-Dawley rats (3). There are at least four binding-sites linked to calmodulin $(\mathrm{CaM})$ and several potential CaM-dependent protein kinase II (CaMKII)-mediated phosphorylation sites in $\mathrm{CaV} 1.2$ (8-11). Binding of $\mathrm{Ca}^{2+}$ produces a conformational change in $\mathrm{CaM}$, exposing hydrophobic residues that promote interactions of the $\mathrm{Ca}^{2+} / \mathrm{CaM}$ complex with $\mathrm{CaV} 1.2$ (12). The $\mathrm{Ca}^{2+} / \mathrm{CaM}$ complex can enhance the affinity of $\mathrm{CaM}$ and the activity of CaV1.2 (13-16). Thus, CaM is important as a $\mathrm{Ca}^{2+}$ sensor for $\mathrm{Ca}^{2+}$-dependent facilitation and inactivation $(17,18)$. CaMKII is a multifunctional serine/threonine kinase, which can mediate several $\mathrm{Ca}^{2+}$-dependent neuronal processes, and it accounts for $0.5-1.0 \%$ of total brain protein and up to $2 \%$ of hippocampal protein $(19,20)$. CaMKII is activated by auto-phosphorylation when it is combined with the $\mathrm{Ca}^{2+} / \mathrm{CaM}$ complex. Additionally, phosphorylated-CaMKII (p-CaMKII) exhibits its biological activity by the phosphorylation of other target proteins $(21,22)$. With the involvement of CaMKII, the activity of $\mathrm{CaV} 1.2$ is promoted by $\mathrm{CaM}(23,24)$. A previous 
study demonstrated immediate inhibition of cortical and hippocampal CaM kinase II activity in homogenate following the development of status epilepticus in a rat pilocarpine model (25). However, the roles of CaV1.2, CaM and CaMKII, and their interactions in epilepsy are controversial and remain to be fully elucidated. The tremor rat model (TRM; tm/tm) is an animal model of epilepsy, which is a genetic mutant first discovered in a Kyoto-Wistar colony (26). TRM is regarded as a useful model of epilepsy due to its similarity in pathogenesis and treatment to the human condition (27). Hippocampal neurons exposed to $\mathrm{Mg}^{2+}$-free solution are well suited to biochemical and electrophysiological investigations to elucidate the cellular mechanisms, which lead to epileptogenesis (28), as the spontaneous epileptiform discharges produced by hippocampal neurons exposed to $\mathrm{Mg}^{2+}$-free solution is similar to the electrical activity of epileptic seizures in humans. Thus, the aim of the present study was to investigate the alterations of the selected $\mathrm{Ca}^{2+} / \mathrm{CaV} 1.2 / \mathrm{CaM} / \mathrm{CaMKII}$ pathway in the TRM and in cultured hippocampal neurons exposed to $\mathrm{Mg}^{2+}$-free solution, in vivo and in vitro, respectively. These investigations aimed to obtain an insight into the pathways in producing neuronal excitability.

\section{Materials and methods}

Animals. The TRM is an animal model of epilepsy and the tm genetic mutant was identified in a Kyoto-Wistar colony (29). In the present study, 15 normal Wistar rats and 15 TRMs aged between 9 and 12 weeks were housed in individual cages under a controlled environment (12:12 h light/dark cycle, $50-70 \%$ humidity, $24^{\circ} \mathrm{C}$ ) with free access to food and water. The present study was performed in strict accordance with the recommendations in the Guide for the Care and Use of Laboratory Animals of the National Institutes of Health $(15,16)$. The animal use protocol was reviewed and approved by the Institutional Animal Care and Use Committee of China Medical University (Shenyang, China).

Electroencephalographic (EEG) determination and evaluation. The experimental animals (five animals per group) were anesthetized with $10 \%$ chloral hydrate (intraperitonal, $0.3 \mathrm{ml} / 100 \mathrm{~g}$ ) and the animals were implanted with EEG electrodes (BL-420F; Taimeng Co., Ltd., Chengdu, China). Cortical and hippocampal electrodes were chronically implanted onto the cortex $(3.0 \mathrm{mM}$ lateral and $3.0 \mathrm{mM}$ rostral to the bregma on the cranium) and in the left hippocampus $(2.0 \mathrm{mM}$ lateral and $4.0 \mathrm{mM}$ caudal to the bregma and $3.0 \mathrm{mM}$ from the cortical surface), respectively (30). Over the 7 days following this procedure, the EEG was recorded using a pen-writing polygraph. Following habituation of the rats in a soundproof box $(40 \times 40 \times 40 \mathrm{~cm})$ for $>20 \mathrm{~min}$, the EEG was recorded for $30 \mathrm{~min}$. The rat was exposed to puff stimulation on the face by a researcher every $5 \mathrm{~min}$ to ensure the animal remained aroused during the recording period. Changes in the EEG during absence-like seizures consistently correlated with the abnormal seizure behavior, as described previously (29). When 5-7 Hz spike-wave-like complexes in the cortical and hippocampal EEG lasted for $>1 \mathrm{sec}$, the response was considered as one absence-like seizure. When the time interval between two independent 5-7 Hz spike-wave-like complexes was $<1 \mathrm{sec}$, the two events were considered as a single seizure.
Primary neuronal cell cultures. Hippocampal neuronal cells, which were obtained from rats born within 1 day of each other, were dissociated in Hanks' balanced salt solution containing $0.125 \%$ trypsin (Sigma-Aldrich, St. Louis, MO, USA) for $10 \mathrm{~min}$ at $37^{\circ} \mathrm{C}$. The cells were then plated onto dishes at $2 \times 10^{5}$ cells $/ \mathrm{cm}^{2}$ in Dulbecco's modified Eagle's medium (Gibco-BRL, Invitrogen Life Technologies, Carlsbad, CA, USA) containing $15 \%$ fetal bovine serum and penicillin-streptomycin, (100 U/ml, Gibco-BRL). Following plating for $24 \mathrm{~h}$, the medium was replaced with Neurobasal ${ }^{\mathrm{TM}}$ medium supplemented with 2\% B27 (Gibco-BRL). The hippocampal neuronal cell media was refreshed every 3-4 days. Hippocampal neurons at the 12th day of in vitro culture were used in the following experiments.

Establishment of the hippocampalneuronal culture model. The in vitro hippocampal neuronal culture model was established according to Sombati's method (31). For primary neuronal cell cultures, maintenance medium was replaced with physiological recording solution for $3 \mathrm{~h}$ (Beyotime Institute of Biotechnology, Haimen, China) with or without $\mathrm{MgCl}_{2}(1 \mathrm{mM})$. The solution contained $145 \mathrm{mM} \mathrm{NaCl}, 2.5 \mathrm{mM} \mathrm{KCl}, 10 \mathrm{mM}$ HEPES, $2 \mathrm{mM}$ $\mathrm{CaCl}_{2}, 10 \mathrm{mM}$ glucose and $0.002 \mathrm{mM}$ glycine (pH 7.3), the osmolarity of which was adjusted to $290 \pm 10$ mOsm using sucrose. Continuous epileptiform high-frequency bursts were induced by exposing the neuronal cultures to physiological recording solution without $\mathrm{MgCl}_{2}\left(\mathrm{Mg}^{2+}\right.$-free $)$ for $3 \mathrm{~h}$, following which the culture was exposed to physiological recording solution. For double-labeling immunofluorescence and western blotting, the cultures were exposed to physiological solution for $8 \mathrm{~h}$ following treatment with $\mathrm{Mg}^{2+}$-free solution for $3 \mathrm{~h}$ prior to use of the hippocampal neurons in these experiments. For measurement of intracellular calcium concentration, the cultures were exposed to $\mathrm{Mg}^{2+}$-free solution of $3 \mathrm{~h}$, following which the hippocampal neurons were used immediately.

Electrophysiological recordings. The electrophysiological recording method used in the present study was that used in our previous study (32). The extracellular bath contained $135 \mathrm{mM} \mathrm{NaCl}, 5.4 \mathrm{mM} \mathrm{KCl}, 1.0 \mathrm{mM} \mathrm{MgCl}, 0.33 \mathrm{mM}$ $\mathrm{NaH}_{2} \mathrm{PO}_{4}, 10 \mathrm{mM}$ HEPES and $5.5 \mathrm{mM}$ glucose $(\mathrm{pH} 7.4$; $\mathrm{NaOH})$. The pipette solution contained $50 \mathrm{mM}$ K-Aspartate, $20 \mathrm{mM} \mathrm{KCl}, 20 \mathrm{mM}$ HEPES, $1 \mathrm{mM}$ EGTA, $1 \mathrm{mM} \mathrm{MgCl}$, $0.2 \mathrm{mM} \mathrm{CaCl}_{2}, 13.6 \mathrm{mM} \mathrm{NaCl}$ and $3 \mathrm{mM} \mathrm{K} 2 \mathrm{ATP} 3$ (pH 7.4; $\mathrm{KOH}$; Beyotime Institute of Biotechnology). Patch-clamp electrodes were obtained with capillary tubes pulled with a P-97 puller (Gibco-BRL). The electrodes had a resistance of 2.5-4 M . Patch clamp was performed using an AxoPatch 200B amplifier (Axon Instruments, Foster City, CA, USA). To record action potential, cultures, including the normal cultured neurons and the neurons treated with $\mathrm{Mg}^{2+}$-free solution, were transferred to the stage of an inverted microscope (TMS-1015, Olympus, Tokyo, Japan). Patch-clamp was performed utilizing the whole-cell current-clamp gap-free recording mode.

Western blot analysis. Proteins from the tissues and neurons were extracted by lysis in radioimmunoprecipitation assay buffer (Beyotime Institute of Biotechnology) with ultrasonication, followed by centrifugation and retrieval of the supernatant. The concentrations of extracted proteins from the 
tissues and neurons were determined using a bicinchoninic acid protein assay kit (Beyotime Institute of Biotechnology). The protein samples (50 $\mu \mathrm{g}$ per lane) were separated by $10 \%$ SDS-PAGE (Beyotime Institute of Biotechnology) and transferred onto polyvinylidene difluoride membranes (Motimo Membrane Technology Co., Ltd., Tianjin, China). The membranes were blocked for $1 \mathrm{~h}$ at room temperature with $5 \%$ bovine serum albumin (BSA) in tris-buffered saline with Tween 20 (TTBS; Beyotime Institute of Biotechnology) containing $50 \mathrm{mM}$ Tris- $\mathrm{HCl} ; 0.1 \%$ Tween-20 and $154 \mathrm{mM} \mathrm{NaCl}$ (pH 7.4), followed by $2 \mathrm{~h}$ incubation. The membranes were then incubated overnight at $4^{\circ} \mathrm{C}$ in TTBS containing the following primary antibodies: Rabbit anti-CaV1.2 (1:500; cat no. ab-81095; Abcam, Cambridge, MA, USA), rabbit anti-CaMKII (1:500; cat no. sc-9035; Santa Cruz Biotechnology, Inc., Dallas, TX, USA), rabbit anti-p-CaMKII (1:500; cat no. sc-3228; Santa Cruz Biotechnology, Inc.; the epitope corresponding to a short amino acid sequence containing phosphorylated Thr-286 of CaMKII $\alpha)$, mouse anti-CaM (1:800; cat no. sc-137079; Santa Cruz Biotechnology, Inc.) and $\beta$-actin (1:1,000; cat no. sc-47778; Santa Cruz Biotechnology, Inc.). Following several washes in TTBS, the membranes were incubated for $1 \mathrm{~h}$ at room temperature in horseradish peroxidase-conjugated goat anti-mouse IgG or horseradish peroxidase-conjugated goat anti-rabbit IgG (1:5,000; cat nos. sc-2005 and sc-2054, respectively; Santa Cruz Biotechnology, Inc.) for $2 \mathrm{~h}$ at room temperature. Immunoreactive bands were visualized using an enhanced chemiluminescence kit. The levels of protein were evaluated by measuring the optical densities of the protein bands using Scion Image (4.03) for Windows image-analysis software. $\beta$-actin was used as a control to demonstrate that equal quantities of protein were loaded. Similarly, CaMKII was used as a control to demonstrate that equal quantities of $\mathrm{p}$-CaMKII were loaded.

Double-labeling immunofluorescence. The TRMs and control rats were anesthetized with $10 \%$ chloral hydrate (i.p., $0.35 \mathrm{ml} / 100 \mathrm{~g}$ ). Following intracardial perfusion with $4 \%$ paraformaldehyde, the brains of the rats were rapidly removed and placed in $4 \%$ paraformaldehyde solution for $24 \mathrm{~h}$ at room temperature and $30 \%$ sucrose solution for $24 \mathrm{~h}$ at $4^{\circ} \mathrm{C}$. The dehydrated-fixed brains were then frozen and $10-\mu \mathrm{m}$ serial coronal sections were cut using a cryostat (CM1900 UV; Leica Microsystems GmbH, Wetzlar, Germany). These sections, and the $\mathrm{Mg}^{2+}$-free treated and normal hippocampal neurons, were rinsed in phosphate-buffered saline (PBS; 0.01 M; pH 7.4) for $15 \mathrm{~min}$ and incubated in PBS (0.01 M; pH 7.4), which was supplemented with $0.25 \%$ Triton X-100 (Sigma-Aldrich) and $10 \%$ BSA (Gibco-BRL) for $1 \mathrm{~h}$ for blocking and penetration. The sections and neurons were then incubated overnight at $4^{\circ} \mathrm{C}$ in a mixture of the following primary antibodies: Mouse anti-CaM (1:100; Santa Cruz Biotechnology, Inc.) and rabbit anti-CaV1.2 (1:80; Abcam) or mouse anti-CaM (1:100; Santa Cruz Biotechnology, Inc.) and rabbit anti p-CaMKII (1:100; Santa Cruz Biotechnology, Inc.). PBS without primary antibodies was used as a negative control. Following rinsing with $0.01 \mathrm{M}$ PBS three times, for $5 \mathrm{~min}$ each, the sections and neurons were incubated with fluorescein isothiocyanate (FITC)- and Cy3-conjugated goat anti-mouse or anti-rabbit antibodies (1:200; ZSGB-BIO, Beijing, China) for $2 \mathrm{~h}$ at room temperature in the dark. Finally, sections from different brain regions, including the hippocampus (CA1, CA3 and DG), temporal cortex and cerebellum, were examined. The sections and neurons were examined using a Confocal laser scanning biological microscope (Fluoview FV500; Olympus Corporation, Tokyo, Japan). CaV1.2 and p-CaMKII were labeled with FITC-emitting green light, CaM was labeled with tetramethylrhodamine-emitting red light, with yellow light representing the co-localization of $\mathrm{CaV} 1.2$ and $\mathrm{CaM}$ or p-CaMKII and CaM. The co-localized cells that were clearly yellow were selected as positive cells, and the number of positive cells in every 100 cells was determined.

Acute dissociation of neurons. Acute dissociation of neurons was performed using a previous method with certain modifications (33). The experimental animals were anesthetized with $10 \%$ chloral hydrate (intraperitoneal, $0.3 \mathrm{ml} / 100 \mathrm{~g}$ ) and then quickly sacrificed by decapitation. The brains were rapidly removed and placed in Hank's balanced salt solution (Gibco Life Technologies). The tissues (hippocampus, temporal cortex and cerebellum) were separated and cut into $400 \mu \mathrm{m}$-thick slices. These slices were incubated in artificial cerebrospinal fluid (Beyotime Institute of Biotechnology) containing $126 \mathrm{mM}$

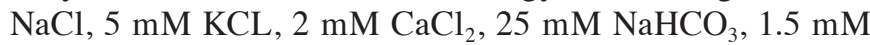
$\mathrm{NaH}_{2} \mathrm{PO}_{4}, 2 \mathrm{mM} \mathrm{MgSO}$ and $10 \mathrm{mM}$ glucose $\left(32^{\circ} \mathrm{C} ; 5 \% \mathrm{CO}_{2}\right.$; $\mathrm{pH}$ adjusted to 7.4 with $\mathrm{NaOH}$ ) for at least $1 \mathrm{~h}$. The tissue slices were dissociated using $0.125 \%$ trypsin (Sigma-Aldrich) for $30 \mathrm{~min}$ at $37^{\circ} \mathrm{C}$, and the dissociated tissues were then rinsed three times in extracellular fluid containing $130 \mathrm{mM} \mathrm{NaCl}$; $5.4 \mathrm{mM} \mathrm{KCl} ; 1 \mathrm{mM} \mathrm{MgCl}$; $1 \mathrm{mM} \mathrm{CaCl}_{2} ; 10 \mathrm{mM}$ HEPES and $25 \mathrm{mM}$ glucose $\left(32^{\circ} \mathrm{C} ; 5 \% \mathrm{CO}_{2} ; \mathrm{pH}\right.$ adjusted to 7.4 with $\mathrm{NaOH}$ ), and triturated mechanically with a graded series of fire-polished Pasteur pipettes of 500, 300 and $150 \mu \mathrm{m}$ (Leiqi Experiment Equipment Co., Ltd., Hangzhou, China, successively. Following standing for $2 \mathrm{~min}$, the upper cells in the cell suspension were plated onto culture dishes $\left(1 \times 10^{6}\right.$ cells $\left./ \mathrm{ml}\right)$ in extracellular fluid. The acute isolated neurons were used within $6 \mathrm{~h}$. All experimental procedures were maintained in a humidified atmosphere under $5 \% \mathrm{CO}_{2}$.

Measurement of intracellular calcium concentration $\left(\left[\mathrm{Ca}^{2+}\right] \mathrm{i}\right)$. The measurement of $\left[\mathrm{Ca}^{2+}\right]$ I was performed, according to that described in our previous study (34). The acutely dissociated neurons and $\mathrm{Mg}^{2+}$-free treated hippocampal neurons were incubated for $20 \mathrm{~min}$ with $5 \mu \mathrm{m}$ fluo-3 acetoxymethylester (fluo-3/AM; Molecular Probes Life Technologies, Carlsbad, $\mathrm{CA}$, USA; $32^{\circ} \mathrm{C} ; 5 \% \mathrm{CO}_{2} ; \mathrm{pH}$ adjusted to 7.4 with $\left.\mathrm{NaOH}\right)$. The neurons of the control group and model group were plated into two cell culture cover glasses in the same dish. Thus, the control and model neurons were treated using the same procedure. The labeled neurons were then rinsed three times with PBS and cultured for $30 \mathrm{~min}$ to exclude non-specific staining of the extracellular fluid $\left(32^{\circ} \mathrm{C} ; 5 \% \mathrm{CO}_{2}\right)$. The preparations were observed and quantitatively analyzed using a confocal laser scanning biological microscope (Fluoview FV500; Olympus, Corporation). The visual field was selected where at least five neurons contained fluo-3/AM, which was excited by the $488 \mathrm{~nm}$ line of a $200 \mathrm{~mW}$ argon ion laser and captured at wavelengths $>505 \mathrm{~nm}$. The data were expressed as relative fluorescence intensities. Confocal imaging was performed on three separate fields of cells for each group. The concentration 


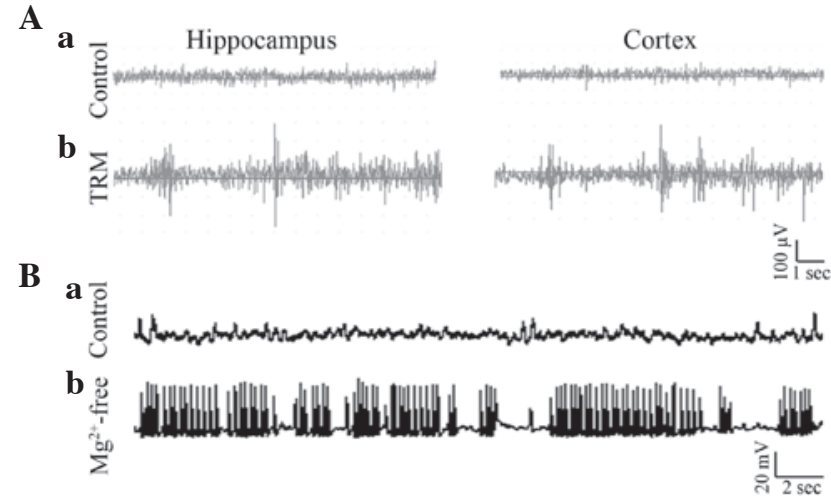

Figure 1. Electroencephalogram recording of the TRM and induction of 'epileptiform discharge' in the cultured hippocampal neurons by $\mathrm{Mg}^{2+}$-free treatment. (A) In the TRM, (a) normal discharge was detected in the control rat hippocampus and cerebral cortex. (b) a $6 \mathrm{~Hz}$ spike and wave complex was detected during absence-like seizure in the TRM hippocampus and cerebral cortex. (B) In the neuron model, (a) occasional spontaneous action potentials were detected in the normal neuron; (b) spontaneous recurrent 'epileptiform discharge' was detected in a $\mathrm{Mg}^{2+}$-free treated neuron. TRM, tremor rat model.

of intracellular $\mathrm{Ca}^{2+}$ was expressed as the relative fluorescent intensity using ImageJ 1.46 software (National Institutes of Health, Bethesda, MD, USA).

Statistical analysis. Values are expressed as the mean \pm standard deviation, and statistical analysis were performed using SPSS 13.0 statistical software (SPSS, Inc., Chicago, IL, USA). Statistical significance was determined using Student's $t$-test and one-way analysis of variance was used for comparisons. $\mathrm{P}<0.05$ was considered to indicate a statistically significant difference.

\section{Results}

Spontaneous discharge activity in the EEG recording in the $T R M$ and $\mathrm{Mg}^{2+}$-free treatment model. The EEG recording of The control rats and TRMs were detected in the hippocampus and cerebral cortex, respectively. It did not reveal any abnormal discharges in The control rat hippocampus or cerebral cortex (Fig. 1Aa), however, a $6 \mathrm{~Hz}$ spike and wave complex was recorded during absence-like seizure in the TRM hippocampus and cerebral cortex (Fig. 1Ab). In addition, the whole-cell current-clamp technique was used to record the electrical physiological activities of normal neurons $(\mathrm{n}=6)$ and $\mathrm{Mg}^{2+}$-free treated neurons $(\mathrm{n}=6)$. The results demonstrated that representative neurons during $3 \mathrm{~h}$ exposure to physiological recording solution containing $1 \mathrm{mM} \mathrm{MgCl}$ produced a normal baseline activity, presenting with occasional action potentials (Fig. 1Ba). However, exposure of the $\mathrm{Mg}^{2+}$-free treated neurons, which were exposed for $3 \mathrm{~h}$ to $\mathrm{Mg}^{2+}$-free recording solution, produced continuous high frequency epileptiform discharges (Fig. 1Bb). These data indicated that the in vivo and in vitro modelS of epileptic discharge in the present study had been established successfully.

Abnormal protein expression of CaV1.2, CaM, p-CaMKII and CaMKII in the TRM and $\mathrm{Mg}^{2+}$-free treatment model. Western blot analysis was performed to quantify and compare selected the protein expression levels in the TRMs $(n=6)$ and control rats $(n=6)$. The western blot was probed with antibodies to CaV1.2, CaM, p-CaMKII and CaMKII,
$\mathbf{A}$
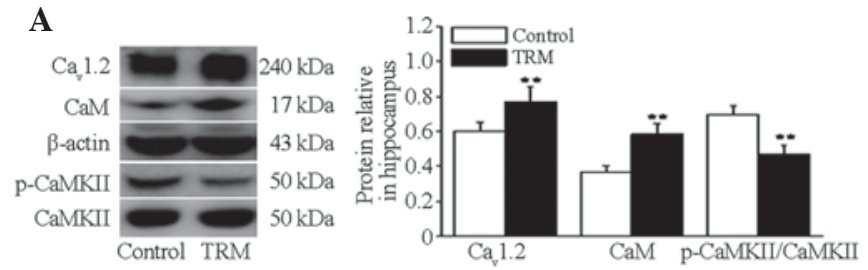

B
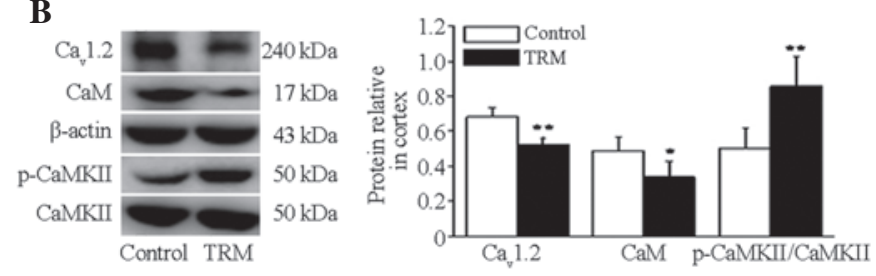

C
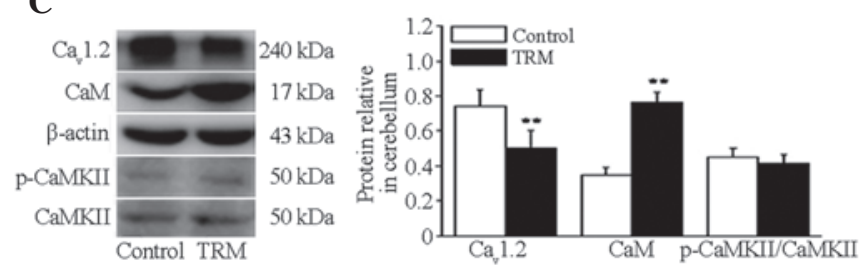

D
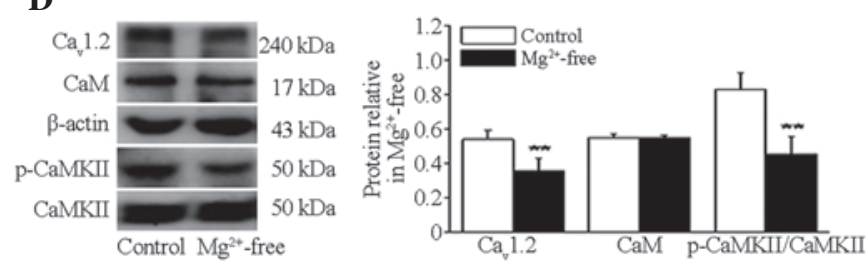

Figure 2. Protein expression levels of CaV1.2, CaM, p-CaMKII and CaMKII in the TRM and hippocampal cultured neurons exposed to $\mathrm{Mg}^{2+}$-free by western blotting. (A) Immunoblots and quantitative analysis of the protein levels of CaV1.2, CaM, p-CaMKII and CaMKII in the TRM hippocampal and control groups $(n=6)$. (B) Immunoblots and quantitative analysis of the protein levels of CaV1.2, CaM, p-CaMKII and CaMKII in the TRM cortex and control groups $(n=6)$. (C) Immunoblots and quantitative analysis of the protein levels of CaV1.2, CaM, p-CaMKII and CaMKII in the TRM cerebellum and control groups $(n=6)$. (D) Immunoblots and quantitative analysis of the protein levels of $\mathrm{CaV} 1.2, \mathrm{CaM}, \mathrm{p}-\mathrm{CaMKII}$ and $\mathrm{CaMKII}$ in the in vitro model $(n=6)$ and control groups $(n=6)$. ${ }^{* *} \mathrm{P}<0.01$, vs. control group; ${ }^{*} \mathrm{P}<0.05$, vs. control group (analysis of variance followed by Student's t-test). Data are presented as the mean \pm standard deviation. TRM, tremor rat model; CaM, calmodulin; CMKII, CaM-dependent protein kinase II; p-, phosphorylated. 

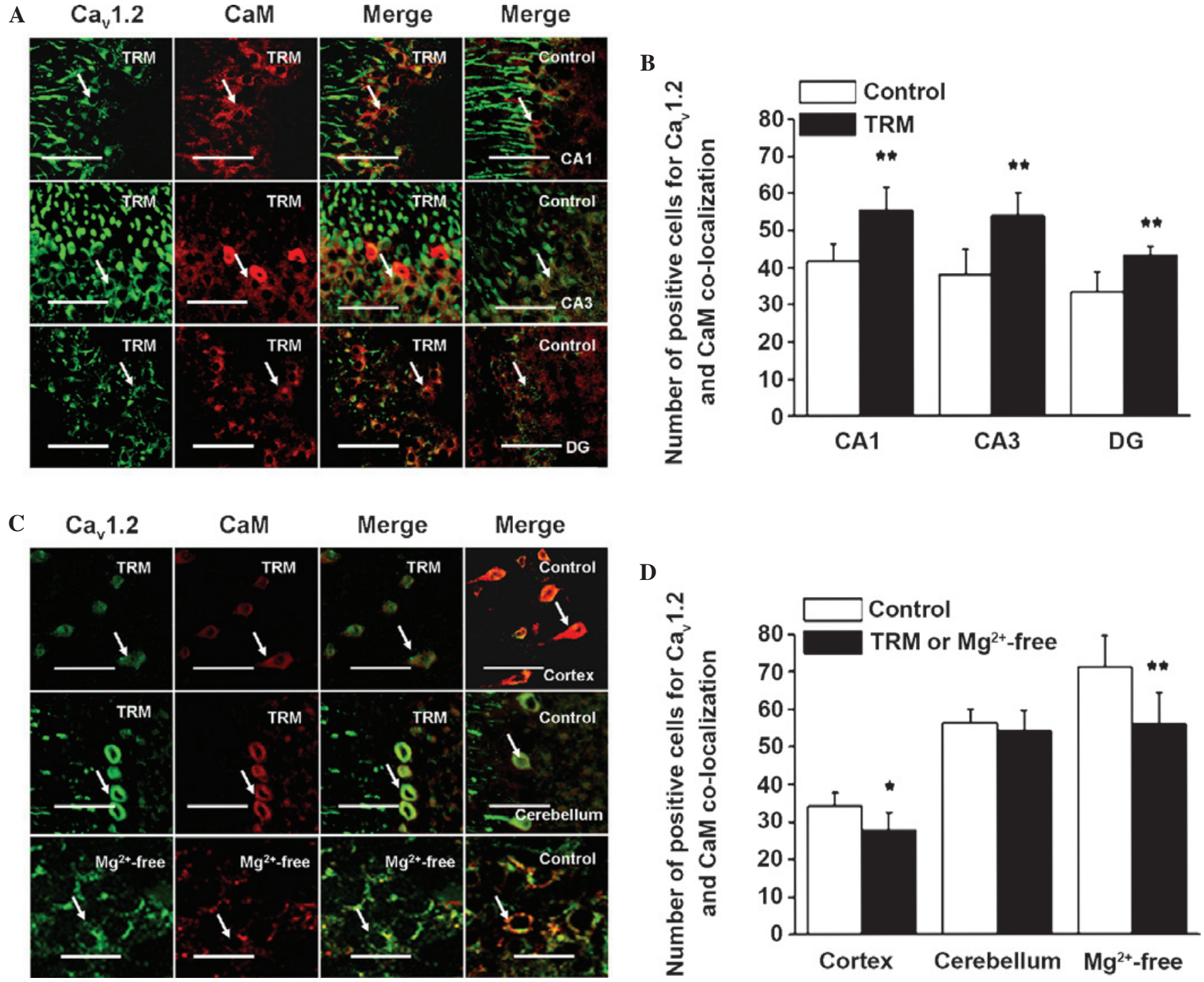

Figure 3. Co-localization of CaV1.2 and CaM in the TRM and in vitro model, detected using immunofluorescence. CaV1.2 was labeled with fluorescein isothiocyanate-emitting green light, $\mathrm{CaM}$ was labeled with tetramethylrhodamine-emitting red light, with yellow light indicating the co-localization of CaV1.2 and CaM. (A) TRM hippocampus CA1, CA3 and DG region. (B) Number of positive cells for CaV1.2-CaM in the TRM hippocampus. ${ }^{* *}<0.01$, vs. control group; ${ }^{*}<0.05$, vs. control group (ANOVA followed by Student's t-test; $\mathrm{n}=5$ ). (C) TRM cortex, cerebellum and Mg ${ }^{2+}$-free hippocampal neurons. (D) Number of positive cells for $\mathrm{CaV} 1.2-\mathrm{CaM}$ in the TRM cortex, cerebellum and in $\mathrm{Mg}^{2+}$-free hippocampal neurons. ${ }^{* *} \mathrm{P}<0.01$, vs. control group; ${ }^{*} \mathrm{P}<0.05$, vs. control group (ANOVA followed by Student's t-test, $\mathrm{n}=5$ ). Scale bar=50 $\mu \mathrm{m}$. Data are presented as the mean \pm standard deviation. TRM, tremor rat model; CaM, calmodulin; CMKII, CaM-dependent protein kinase II; ANOVA, analysis of variance.

and their respective anticipated bands at $240 \mathrm{kDa}, 17 \mathrm{kDa}$ and $50 \mathrm{kDa}$ were detected, respectively. In the TRMs, hippocampal quantification analysis revealed that the levels of expression of $\mathrm{CaV} 1.2(\mathrm{P}=0.0017)$ and $\mathrm{CaM}(\mathrm{P}=0.0001)$ were increased significantly, while those of $\mathrm{p}-\mathrm{CaMKII}(\mathrm{P}=0.0001)$ were decreased significantly, compared with the control rats. No change was observed in the expression of CaMKII $(\mathrm{P}=0.08)$, compared with control groups (Fig. 2A). Notably, the situation was reversed in the protein expression patterns of the TRM temporal cortex. The expression levels of of CaV1.2 $(\mathrm{P}=0.0001)$ and $\mathrm{CaM}(\mathrm{P}=0.0130)$ were significantly lower than those in the control group. Compared with the control rats, the expression of $\mathrm{p}$-CaMKII $(\mathrm{P}=0.0017)$ was increased significantly. No change was detected in the expression of CaMKII $(\mathrm{P}=0.77)$, compared with the control group (Fig. 2B). In addition, these findings verified upregulation of the expression of $\mathrm{CaM}(\mathrm{P}=0.0001)$ and downregulation in the expression of
CaV1.2 ( $\mathrm{P}=0.0019)$ at the protein level in the TRM cerebellum. No changes occurred in the protein expression of $\mathrm{p}$-CaMKII $(\mathrm{P}=0.3700)$ or $\mathrm{CaMKII}(\mathrm{P}=0.72)$, compared with the control group (Fig. 2C). In the hippocampal $\mathrm{Mg}^{2+}$-free neuron epileptiform discharge model, no significant differences were observed in the expression of CaM $(\mathrm{P}=0.9799)$, compared with the control neurons, while $\mathrm{p}$-CaMKII $(\mathrm{P}=0.0006)$ and CaV1.2 ( $\mathrm{P}=0.0001)$ were decreased, compared with the control neurons. No change was observed in the protein expression of CaMKII ( $\mathrm{P}=0.43)$, compared with the control group (Fig. 2D).

Co-localization of CaV1.2 with CaM, and p-CaMKII with CaM in the TRM and $M^{2+}$-free treatment model. Immunofluorescence analyses were performed in the two model $(n=5)$ and control group $(n=5)$ using anti-CaV1.2, anti-CaM and anti-p-CaMKII to detect the distributions and expression levels. As shown in Fig. 3A, in the TRM 

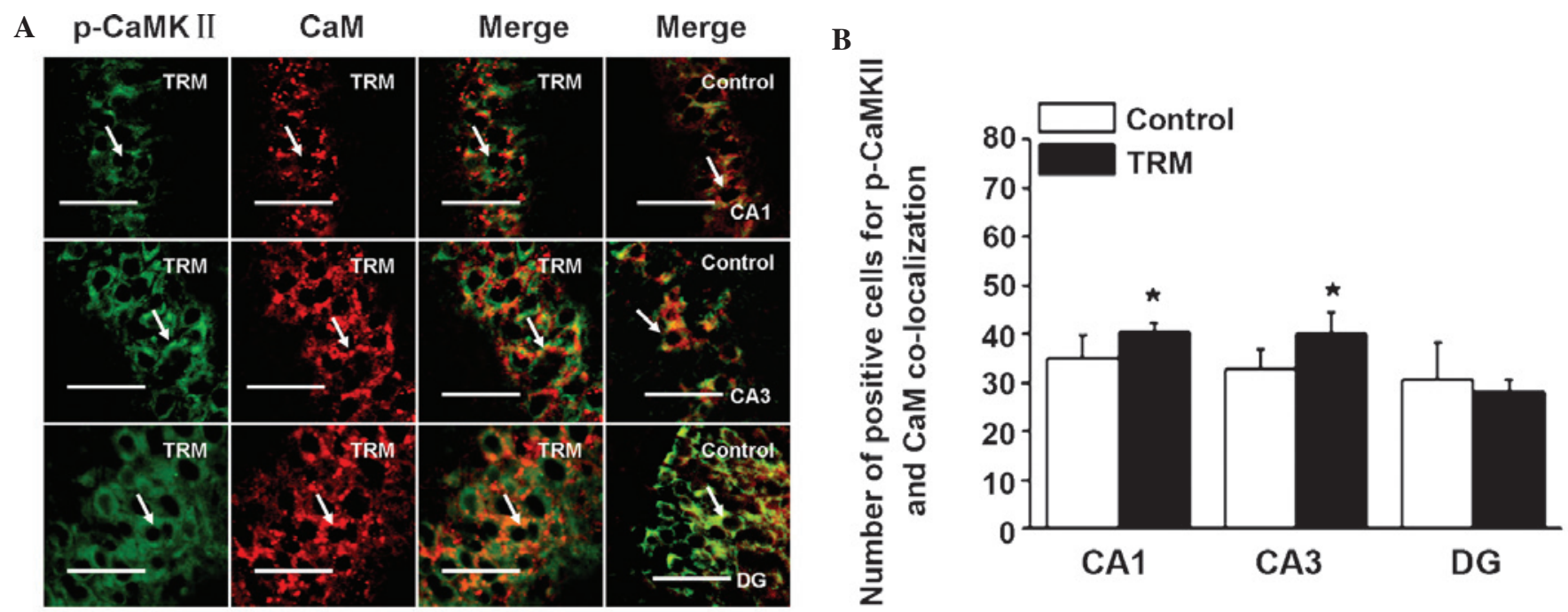

C
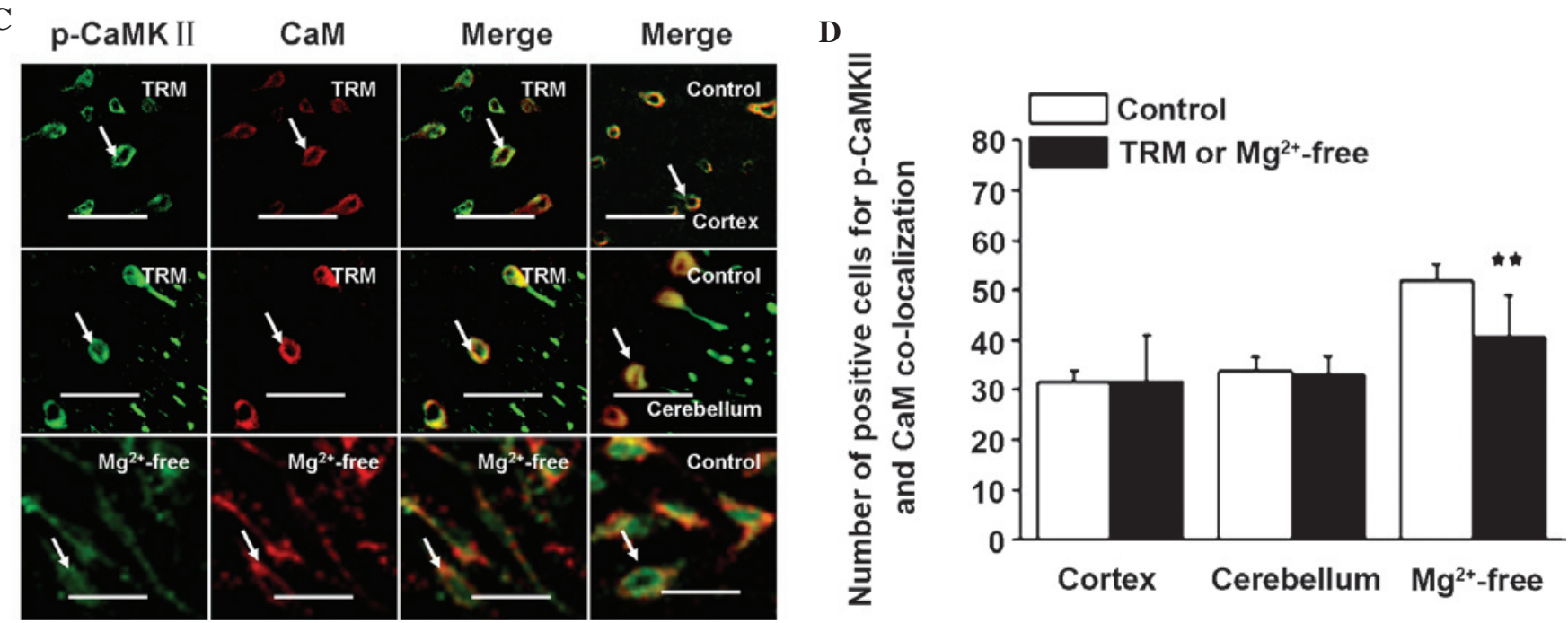

Figure 4. Co-localization of p-CaMKII and CaM in the TRM and in vitro model, detected using immunofluorescence. The p-CaMKII was labeled with fluorescein isothiocyanate-emitting green light and $\mathrm{CaM}$ was labeled with tetramethylrhodamine-emitting red light, with yellow light indicating the co-localization of p-CaMKII and CaM. (A) TRM hippocampus CA1, CA3 and DG regions. (B) Number of positive cells for p-CaMKII-CaM in the TRM hippocampus. ${ }^{* *} \mathrm{P}<0.01$, vs. control group; ${ }^{P} \mathrm{P}<0.05$, vs. control group (ANOVA followed by Student's t-test; $\mathrm{n}=5$ ). (C) TRM cortex, cerebellum and $\mathrm{Mg}^{2+}$-free hippocampal neurons. (D) Number of positive cells for $\mathrm{p}-\mathrm{CaMKII-CaM}$ in the TRM cortex, cerebellum and in $\mathrm{Mg}^{2+}$-free hippocampal neurons. ${ }^{* *} \mathrm{P}<0.01$, vs. control group; ${ }^{*} \mathrm{P}<0.05$, vs. control group (ANOVA followed by Student's $t$-test; $\mathrm{n}=5$ ). Scale bar $=50 \mu \mathrm{m}$. Data are presented as the mean \pm standard deviation. TRM, tremor rat model; CaM, calmodulin; CMKII, CaM-dependent protein kinase II; p-, phosphorylated.

hippocampus, compared to control group, the CaV1.2 and $\mathrm{CaM}$ immunopositive neurons were stained markedly in CA1 and CA3 areas, while in DG areas, they were not expressed as highly as they were in the CA1 or CA 3 areas. CaV1.2 was concentrated in the soma and proximal dendrites of the pyramidal neurons (green), and CaM was primarily localized to the cytoplasm (red). It was of interest to note that CaV1.2 co-localized with CaM. Overlapping localization of these proteins (yellow) were evident in the CA1 $(\mathrm{P}=0.0044), \mathrm{CA} 3$ $(\mathrm{P}=0.0050)$ and $\mathrm{DG}(\mathrm{P}=0.0060)$ areas when the images of their individual staining patterns were merged (Fig. 3B). As indicated in Fig. $3 \mathrm{C}$ and D, in the TRM cortex, the number of co-localization cells for CaV1.2-CaM was decreased, compared with that of the normal rats $(\mathrm{P}=0.0417)$. In the cerebellum, the number of co-localization cells for $\mathrm{CaV} 1.2-\mathrm{CaM}$ was not changed, compared with the controls $(\mathrm{P}=0.4771)$. In the $\mathrm{Mg}^{2+}$-free treated neuron model, CaV1.2 was localized to the cell membrane, while CaM was localized to the cell membrane and the cytoplasm. The number of co-localization cells for $\mathrm{CaV} 1.2-\mathrm{CaM}$ in the $\mathrm{Mg}^{2+}$-free treated model was decreased compared with normal neurons $(\mathrm{P}=0.0075)$. In addition, p-CaMKII immunopositive neurons (green) were localized in the cytoplasm of cells in hippocampus. Compared with the controls, the numbers of co-localization cells of CaM-p-CaMKII in the CA1 $(\mathrm{P}=0.0480)$ and CA3 $(\mathrm{P}=0.0289)$ of the TRM hippocampus were increased, respectively, however, there was no change in the $\mathrm{DG}(\mathrm{P}=0.5675$, Fig. 4A and B). It was clear that the distribution pattern of p-CaMKII was widely localized in the cytoplasm of cortical cells, which was similar to that observed in the hippocampus (Fig. 4C). There was no significant change of overlapping localization of p-CaMKII and CaM in the temporal cortex $(\mathrm{P}=0.9631$; Fig. 4C and D). In the cerebellum of the TRM, the number of CaM-p-CaMKII-positive cells was also 
A
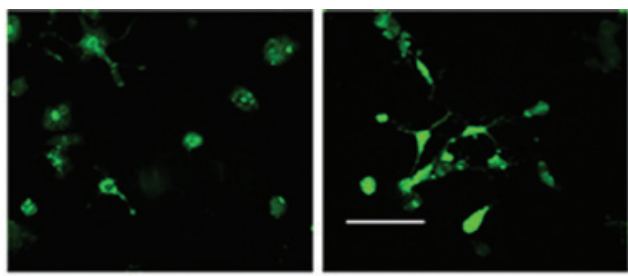

B
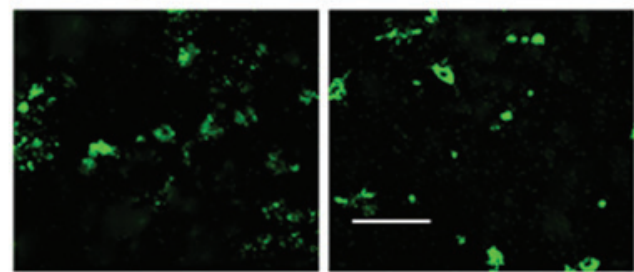

C

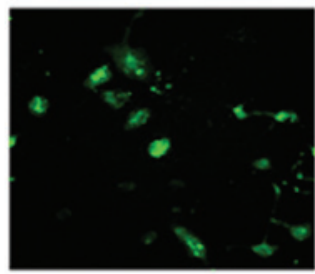

Control

D

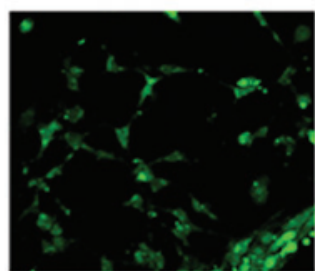

Control

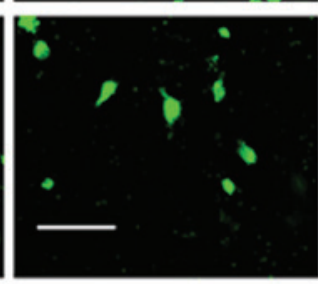

TRM

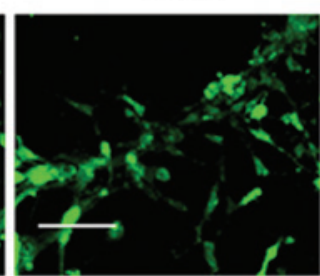

$\mathrm{Mg}^{2+}$-free
$\mathbf{E}$

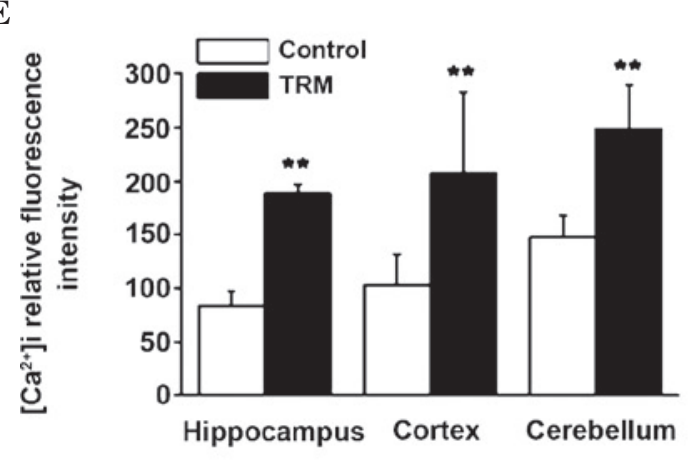

F

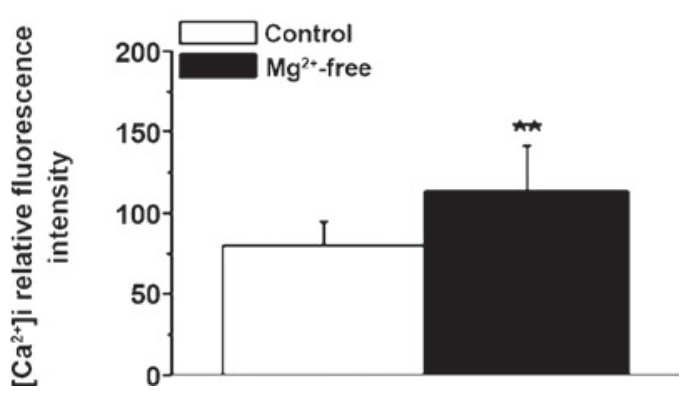

Figure $5 .\left[\mathrm{Ca}^{2+}\right]_{\mathrm{i}}$ relative fluorescence intensity in the TRM and the cultured hippocampal neurons exposed to $\mathrm{Mg}^{2+}$-free. (A) $\left[\mathrm{Ca}^{2+}\right]_{\mathrm{i}}$ relative fluorescence intensity in the TRM hippocampus. (B) $\left[\mathrm{Ca}^{2+}\right]_{\mathrm{i}}$ relative fluorescence intensity in the TRM cortex. (C) $\left[\mathrm{Ca}^{2+}\right]_{i}$ relative fluorescence intensity in the TRM cerebellum. (D) $\left[\mathrm{Ca}^{2+}\right]_{\mathrm{i}}$ relative fluorescence intensity in the $\mathrm{Mg}^{2+}$-free hippocampal neurons. (E) Quantification of the relative fluorescence intensities in the TRM, compared with the control and (F) $\mathrm{Mg}^{2+}$-free hippocampal neurons, compared with the control. ${ }^{* *} \mathrm{P}<0.01$, vs. control (analysis of variance followed by Student's t-test; $\mathrm{n}=5$ ). Scale bar $=50 \mu \mathrm{m}$ Data are presented as the mean \pm standard deviation. TRM, tremor rat model. unchanged ( $\mathrm{P}=0.7792$; Fig. $4 \mathrm{C}$ and $\mathrm{D})$. However, in the in vitro model, there was a decrease in the number of p-CaMKII and $\mathrm{CaM}$ co-localization neurons, compared with the controls $(\mathrm{P}=0.0059$; Fig. 4C and D).

Measurement of intracellular calcium concentration in the TRM and $\mathrm{Mg}^{2+}$-free treatment model. Compared with the controls $(n=5)$, the $\left[\mathrm{Ca}^{2+}\right]$ I relative fluorescence intensity of the model groups $(n=5)$, including the TRMs (hippocampus, cortex and cerebellum; Fig. 5A-C) and $\mathrm{Mg}^{2+}$-free hippocampal neurons (Fig. 5D) were increased, as shown in Fig. 5E and F.

\section{Discussion}

The predominant aims of the present study were to examine the changes in $\mathrm{Ca}^{2+} / \mathrm{CaV} 1.2 / \mathrm{CaM} / \mathrm{CaMKII}$ in the TRM and in the hippocampal $\mathrm{Mg}^{2+}$-free neuron epileptiform discharge models; and to demonstrate the possible correlation between CaV1.2 and the CaM/CaMKII pathway in these models. Epileptic models are fundamental to the investigation of the pathogenesis and possible treatments for epilepsy. TRMs were used in the present study as they are similar to the relevant human disease (27). TRM is an ideal model for the investigation of absence-like seizures, and seizures linked with the tm mutant, which was mapped to rat chromosome 10 (35). Furthermore, the paroxysmal occurrence of a $5-7 \mathrm{~Hz}$ spike-wave complexes can be recorded in the hippocampal and cortical areas after 8 weeks (29). In addition, the hippocampal $\mathrm{Mg}^{2+}$-free neuron epileptiform discharge model is a common model of epileptiform discharge in vitro (36).

In the present study, $\mathrm{Mg}^{2+}$-free treated hippocampal neurons produced continuous high frequency epileptiform discharges, which corresponded to observations in our previous study using whole-cell current-clamp (32). In the present study, the $\left[\mathrm{Ca}^{2+}\right]$ I fluorescence intensity was increased in the TRMs (hippocampus, temporal cortex and cerebellum) and in the in vitro model, indicating that $\mathrm{Ca}^{2+}$ mayt be a key element in the epileptogenesis of these two models. $\left[\mathrm{Ca}^{2+}\right] \mathrm{I}$ led to the depolarization of cells, activating the inflow of $\mathrm{Na}+$ and further enhancing epilepsy $(37,38)$. Previous studies demonstrated that status epilepticus causes sustained elevation of intracellular calcium levels in the hippocampal neuronal culture model $(39,40)$. In addition, calcium influx is enhanced in hippocampal CA3 neurons of spontaneously epileptic rats (41), which is in agreement with the results of the present study. A prominent finding in the present study was that the protein expression of CaV1.2 was increased significantly in the TRM hippocampus. However, the protein expression levels of CaV1.2 were decreased in the cortex, cerebellum and in in vitro culture. Previous studies have demonstrated that VDCC is essential in neuronal excitability (42). Transient and selective upregulation of CaV3.2 subunits on the mRNA and protein levels following status epilepticus causes an increase in cellular T-type $\mathrm{Ca}^{2+}$ currents and a transitional increase in intrinsic burst firing (43). Enhancements of $\mathrm{Ca}^{2+}$ influx into hippocampal CA3 neurons, due to the easier activation properties of VDCCs, are involved in SER epileptic seizures (44). In addition, VDCC currents are enhanced in the hippocampus 
of patients with temporal lobe epilepsy (45). Another study reported that the expression of CaV1.2 was significantly reduced in Stargazer mouse cerebellar synapses, compared with their non-ataxic littermates, however, no differences were detected in hippocampal synapses (5). Accordingly, these findings have indicated the importance of CaV1.2 in the epileptic brain. The increased expression of CaV1.2 in TRM may result in an increase in the number of $\mathrm{Ca}^{2+}$ channels, following which $\mathrm{Ca}^{2+}$ current may be elevated, and a long-lasting depolarization shift accompanied by repetitive firing may be induced, which may contribute to the enhanced neuronal excitability in epilepsy (41). Thus, the present study revealed that the upregulated expression of CaV1.2 in the hippocampus of TRM may be involved in the generation of epileptiform activity and underlie, at least in part, the observed seizure phenotype in TRM.

The present data also demonstrated the upregulation of co-localization of CaM and CaV1.2 in the TRM hippocampus, and the combination of $\mathrm{CaM}$ and $\mathrm{CaV} 1.2$ may activate the $\mathrm{Ca}^{2+}$ channel and, ultimately, elevate the level of excitability in neurons. Notably, the distribution and expression of CaM and CaV1.2 in the cortex was opposite to that observed in the hippocampus in the TRM, indicating a possible compensatory response aimed at counteracting hyperexcitability in the cortex of the TRM. Several previous studies have reported controversy in the change of CaMKII in different models of epilepsy. Selective suppression of CaMKII activity results in alterations in $\mathrm{Ca}^{2+}$ homeostasis and the development of SREDs in hippocampal neurons (46). Additionally, the expression of CaMKII $\alpha$ is decreased in pentylenetetrazol-kindled rats (47). Another study demonstrated that the expression of p-CaMKII is upregulated in dendritic spines during epileptiform activity in vitro (48). This may be due to factors including different epilepsy models and brain regions. The present study demonstrated that the expression of p-CaMKII in the hippocampus was downregulated. This may be due to $\mathrm{Ca}^{2+}$ being overloaded in epilepsy, which upregulated the expression of $\mathrm{CaM}$, following which $\mathrm{Ca}^{2+} / \mathrm{CaM}$-dependent enzymes were adjusted and the activity of CaMKII was restrained. However, the expression of p-CaMKII in the cortex was upregulated, which disagreed with the expression in the hippocampus and may be a compensatory response in the cortex. Notably, the expression levels of p-CaMKII were particularly low in the cerebellum. Thus, sustained $\mathrm{Ca}^{2+}$ overload may have caused a sharp increase in CaMKII auto-phosphorylation, which resulted in the reduction in CaMKII and p-CaMKII. In the in vitro model, the expression levels of p-CaMKII and CaV1.2 were downregulated, while that of $\mathrm{CaM}$ remained unchanged. Similar to previous studies, the reason for this may be that SREDs inhibited the activity of CaMKII and restrained its substrate $(23,24)$.

The limitation of the present study lies in the in vivo and in vitro models, which may represent different types of models. To a certain extent, the hippocampal neuronal culture model can be considered an acute seizures model, and the neurons treated with $\mathrm{Mg}^{2+}$-free solution for $3 \mathrm{~h}$ may be not sufficient to fully undergo the molecular and cellular changes associated with the development of epileptogenesis. By contrast, TRM rats are genetic epileptic animals exhibiting spontaneous seizures, which can be considered a chronic model of epilepsy. Therefore, it is not surprising that the discrepancy was observed in the results of these two models. A noteworthy findings of the present study was that the $\mathrm{CaV} 1.2-\mathrm{CaM}$ and CaMKII-CaM complexes were widely co-localized in the TRM hippocampus, indicating that the association between these proteins may be involved in TRM seizures. The present study hypothesized that when $\left[\mathrm{Ca}^{2+}\right] \mathrm{I}$ increases in TRM, $\mathrm{Ca}^{2+}$ and $\mathrm{CaM}$ are combined to form the $\mathrm{Ca}^{2+} / \mathrm{CaM}$ complex, facilitating the affinity of $\mathrm{CaM}$ and $\mathrm{CaV} 1.2$. Additionally, CaMKII was activated by auto-phosphorylation when it combined with the $\mathrm{Ca}^{2+} / \mathrm{CaM}$ complex. Furthermore, increased $\mathrm{CaM}$ can be co-localized to the membrane with $\mathrm{CaV} 1.2$, leading to the upregulation and increased activity of $\mathrm{CaV} 1.2$, which contribute to enhanced neuronal excitability and results in TRM seizures. Collectively, the present study demonstrated abnormal changes in the $\mathrm{Ca}^{2+} / \mathrm{CaV} 1.2 / \mathrm{CaM} / \mathrm{CaMKII}$ signaling pathway in TRMs and in the hippocampal neuronal culture model. Altering the expression of CaV1.2, CaMKII and CaM may lead these to become potential targets for therapy in epilepsy or seizures. TRMs and the hippocampal neuronal culture model can be screened for effective specific VDCC subtypes for the treatment of epilepsy or seizures.

\section{Acknowledgements}

This study was financially supported by Natural Science Foundation of China (grant nos. 81471323, 81001429 and 31471091). The authors would like to thank Dr Tadao Serikawa (Kyoto University, Kyoto, Japan) for the provision of the TRM strain.

\section{References}

1. Moseley BD, Wirrell EC, Wong-Kisiel LC and Nickels K: Early onset epilepsy is associated with increased mortality: A population-based study. Epilepsy Res 105: 410-414, 2013.

2. Nakatani Y, Masuko H and Amano T: Effect of lamotrigine on $\mathrm{Na}(\mathrm{v}) 1.4$ voltage-gated sodium channels. J Pharmacol Sci 123: 203-206, 2013.

3. N'Gouemo P, Yasuda R and Faingold CL: Seizure susceptibility is associated with altered protein expression of voltage-gated calcium channel subunits in inferior colliculus neurons of the genetically epilepsy-prone rat. Brain Res 1308: 153-157, 2010.

4. Arikkath J and Campbell KP: Auxiliary subunits: Essential components of the voltage-gated calcium channel complex. Curr Opin Neurobiol 13: 298-307, 2003.

5. Leitch B, Shevtsova O, Guevremont D and Williams J: Loss of calcium channels in the cerebellum of the ataxic and epileptic stargazer mutant mouse. Brain Res 1279: 156-167, 2009.

6. Obermair GJ, Szabo Z, Bourinet E and Flucher BE: Differential targeting of the L-type $\mathrm{Ca} 2+$ channel alpha $1 \mathrm{C}(\mathrm{CaV} 1.2)$ to synaptic and extrasynaptic compartments in hippocampal neurons. Eur J Neurosci 19: 2109-2122, 2004.

7. Xu JH, Long L, Tang YC, Hu HT and Tang FR: Ca(v)1.2, $\mathrm{Ca}(\mathrm{v}) 1.3$ and $\mathrm{Ca}(\mathrm{v}) 2.1$ in the mouse hippocampus during and after pilocarpine-induced status epilepticus. Hippocampus 17 : 235-251, 2007.

8. Grueter CE, Abiria SA, Dzhura I, Wu Y, Ham AJ, Mohler PJ, Anderson ME and Colbran RJ: L-type $\mathrm{Ca} 2+$ channel facilitation mediated by phosphorylation of the beta subunit by CaMKII. Mol Cell 23: 641-650, 2006.

9. Hao LY, Wang WY, Minobe E, Han DY, Xu JJ, Kameyama A and Kameyama M: The distinct roles of calmodulin and calmodulin kinase II in the reversal of run-down of L-type $\mathrm{Ca}(2+)$ channels in guinea-pig ventricular myocytes. J Pharmacol Sci 111: 416-425, 2009. 
10. Minobe E, Asmara H, Saud ZA and Kameyama M: Calpastatin domain $\mathrm{L}$ is a partial agonist of the calmodulin-binding site for channel activation in Cav1.2 Ca2+ channels. J Biol Chem 286: 39013-39022, 2011.

11. Wang WY, Hao LY, Minobe E, Saud ZA, Han DY and Kameyama M: CaMKII phosphorylates a threonine residue in the C-terminal tail of Cav1.2 $\mathrm{Ca}(2+)$ channel and modulates the interaction of the channel with calmodulin. J Physiol Sci 59: 283-290, 2009

12. Dolmetsch RE, Pajvani U, Fife K, Spotts JM and Greenberg ME: Signaling to the nucleus by an L-type calcium channel-calmodulin complex through the MAP kinase pathway. Science 294: 333-339, 2001 .

13. Asmara H, Minobe E, Saud ZA and Kameyama M: Interactions of calmodulin with the multiple binding sites of Cav1.2 Ca2+ channels. J Pharmacol Sci 112: 397-404, 2010.

14. Dick IE, Tadross MR, Liang H, Tay LH, Yang W and Yue DT: A modular switch for spatial $\mathrm{Ca} 2+$ selectivity in the calmodulin regulation of $\mathrm{CaV}$ channels. Nature 451: 830-834, 2008.

15. Guo F, Minobe E, Yazawa K, Asmara H, Bai XY, Han DY, Hao LY and Kameyama M: Both N- and C-lobes of calmodulin are required for $\mathrm{Ca} 2+-$ dependent regulations of $\mathrm{CaV} 1.2 \mathrm{Ca} 2+$ channels. Biochem Biophys Res Commun 391: 1170-1176, 2010.

16. Han DY, Minobe E, Wang WY, Guo F, Xu JJ, Hao LY and Kameyama M: Calmodulin- and $\mathrm{Ca} 2+-$ dependent facilitation and inactivation of the Cav1.2 Ca2+ channels in guinea-pig ventricular myocytes. J Pharmacol Sci 112: 310-319, 2010.

17. Peterson BZ, DeMaria CD, Adelman JP and Yue DT: Calmodulin is the $\mathrm{Ca} 2+$ sensor for $\mathrm{Ca} 2+-$ dependent inactivation of L-type calcium channels. Neuron 22: 549-558, 1999.

18. Tang W, Halling DB, Black DJ, Pate P, Zhang JZ, Pedersen S, Altschuld RA and Hamilton SL: Apocalmodulin and Ca2+ calmodulin-binding sites on the CaV1.2 channel. Biophys J 85: $1538-1547,2003$

19. Erondu NE and Kennedy MB: Regional distribution of type II Ca2+/calmodulin-dependent protein kinase in rat brain. J Neurosci 5: 3270-3277, 1985.

20. Zhang L, Kirschstein T, Sommersberg B, Merkens M Manahan-Vaughan D, Elgersma Y and Beck H: Hippocampal synaptic metaplasticity requires inhibitory autophosphorylation of $\mathrm{Ca} 2+/$ calmodulin-dependent kinase II. J Neurosci 25 : $7697-7707,2005$

21. Rich RC and Schulman H: Substrate-directed function of calmodulin in autophosphorylation of $\mathrm{Ca} 2+/ \mathrm{calmod}-$ ulin-dependent protein kinase II. J Biol Chem 273: 28424-28429, 1998.

22. Welsby PJ, Wang H, Wolfe JT, Colbran RJ, Johnson ML and Barrett PQ: A mechanism for the direct regulation of T-type calcium channels by $\mathrm{Ca} 2+/$ calmodulin-dependent kinase II. J Neurosci 23: 10116-10121, 2003.

23. Dzhura I, Wu Y, Colbran RJ, Balser JR and Anderson ME: Calmodulin kinase determines calcium-dependent facilitation of L-type calcium channels. Nat Cell Biol 2: 173-177, 2000.

24. Hudmon A, Schulman H, Kim J, Maltez JM, Tsien RW and Pitt GS: CaMKII tethers to L-type Ca2+ channels, establishing a local and dedicated integrator of $\mathrm{Ca} 2+$ signals for facilitation. J Cell Biol 171: 537-547, 2005

25. Singleton MW, Holbert WH II, Lee AT, Bracey JM and Churn SB: Modulation of CaM kinase II activity is coincident with induction of status epilepticus in the rat pilocarpine model. Epilepsia 46: 1389-1400, 2005.

26. Seki T, Matsubayashi H, Amano T, Kitada K, Serikawa T, Sasa M and Sakai N: Adenoviral gene transfer of aspartoacylase ameliorates tonic convulsions of spontaneously epileptic rats. Neurochem Int 45: 171-178, 2004.

27. Hanaya R, Sasa M, Ujihara H,Fujita Y, Amano T, Matsubayashi $\mathrm{H}$, Serikawa T and Uozumi T: Effect of antiepileptic drugs on absence-like seizures in the tremor rat. Epilepsia 36: 938-942, 1995.

28. Blair RE, Sombati S, Churn SB and Delorenzo RJ: Epileptogenesis causes an N-methyl-d-aspartate receptor/Ca2+-dependent decrease in $\mathrm{Ca} 2+/$ calmodulin-dependent protein kinase II activity in a hippocampal neuronal culture model of spontaneous recurrent epileptiform discharges. Eur J Pharmacol 588: 64-71, 2008

29. Serikawa T, Ohno Y, Sasa M, Yamada J and Takaori S: A new model of petit mal epilepsy: Spontaneous spike and wave discharges in tremor rats. Lab Anim 21: 68-71, 1987.
30. Seki T, Matsubayashi H, Amano T, Kitada K, Serikawa T, Sakai $\mathrm{N}$ and Sasa M: Adenoviral gene transfer of aspartoacylase into the tremor rat, a genetic model of epilepsy, as a trial of gene therapy for inherited epileptic disorder. Neurosci Lett 328: 249-252, 2002.

31. Sombati S and Delorenzo RJ: Recurrent spontaneous seizure activity in hippocampal neuronal networks in culture. J Neurophysiol 73: 1706-1711, 1995.

32. Guo F, Xu X, Cai J, Hu H, Sun W, He G, Shao D, Wang L, Chen T, Shaw C, et al: The up-regulation of voltage-gated sodium channels subtypes coincides with an increased sodium current in hippocampal neuronal culture model. Neurochem Int 62: 287-295, 2013.

33. Li XM, Li JG, Yang JM, Hu P, Li XW, Wang Y, Qin LN and Gao TM: An improved method for acute isolation of neurons from the hippocampus of adult rats suitable for patch-clamping study. Sheng Li Xue Bao 56: 112-117, 2004.

34. Min D, Guo F, Zhu S, Xu X, Mao X, Cao Y, Lv X, Gao Q, Wang L, Chen T,etal: Thealterations of Ca2+/calmodulin/CaMKII/CaV1.2 signaling in experimental models of Alzheimer's disease and vascular dementia. Neurosci Lett 538: 60-65, 2013.

35. Kuramoto T, Mori M, Yamada J and Serikawa T: Tremor and zitter, causative mutant genes for epilepsy with spongiform encephalopathy in spontaneously epileptic rat (SER), are tightly linked to synaptobrevin-2 and prion protein genes, respectively. Biochem Biophys Res Commun 200: 1161-1168, 1994.

36. Cao HY, Jiang YW, Liu ZW and Wu XR: Effect of recurrent epileptiform discharges induced by magnesium-free treatment on developing cortical neurons in vitro. Brain Res Dev Brain Res 142: 1-6, 2003.

37. Badea T, Goldberg J, Mao B and Yuste R: Calcium imaging of epileptiform events with single-cell resolution. J Neurobiol 48: 215-227, 2001

38. Srinivas KV and Sikdar SK: Epileptiform 'activity induces distance-dependent alterations of the $\mathrm{Ca} 2+$ extrusion mechanism in the apical dendrites of subicular pyramidal neurons. Eur J Neurosci 28: 2195-2212, 2008.

39. Pal S, Sombati S, Limbrick DD Jr and DeLorenzo RJ: In vitro status epilepticus causes sustained elevation of intracellular calcium levels in hippocampal neurons. Brain Res 851: 20-31, 1999.

40. Zhang J, Ding MP, Liu Z, Xiao B, Li GL and Zhou FY: Dynamics of calcium in the hippocampal neuronal culture model of epilepsy. Zhongguo Ying Yong Sheng Li Xue Za Zhi 23: 200-203, 2007 (In Chinese).

41. Amano T, Amano H, Matsubayashi H, Ishihara K, Serikawa T and Sasa M: Enhanced $\mathrm{Ca}(2+)$ influx with mossy fiber stimulation in hippocampal CA3 neurons of spontaneously epileptic rats. Brain Res 910: 199-203, 2001.

42. Naderi N, Ahmad-Molaei L, Mazar-Atabaki A, Ronaghi A, Shirazi-zand Z, Motiei-Langroudi SM and Eslahkar S: L-type calcium channel mediates anticonvulsant effect of cannabinoids in acute and chronic murine models of seizure. Neurochem Res 37: 279-287, 2012.

43. Becker AJ, Pitsch J, Sochivko D, Opitz T, Staniek M, Chen CC, Campbell KP, Schoch S, Yaari Y and Beck H: Transcriptional upregulation of Cav3.2 mediates epileptogenesis in the pilocarpine model of epilepsy. J Neurosci 28: 13341-13353, 2008.

44. Yan HD, Ishihara K, Hanaya R, Kurisu K, Serikawa T and Sasa M: Voltage-dependent calcium channel abnormalities in hippocampal CA3 neurons of spontaneously epileptic rats. Epilepsia 48: 758-764, 2007.

45. Lie AA, Blümcke I, Volsen SG, Wiestler OD, Elger CE and Beck H: Distribution of voltage-dependent calcium channel beta subunits in the hippocampus of patients with temporal lobe epilepsy. Neuroscience 93: 449-456, 1999.

46. Carter DS, Haider SN, Blair RE, Deshpande LS, Sombati S and DeLorenzo RJ: Altered calcium/calmodulin kinase II activity changes calcium homeostasis that underlies epileptiform activity in hippocampal neurons in culture. J Pharmacol Exp Ther 319 1021-1031, 2006

47. Wang P, Wang WP, Sun-Zhang, Wang HX, Yan Lou and Fan YH: Impaired spatial learning related with decreased expression of calcium/calmodulin-dependent protein kinase IIalpha and cAMP-response element binding protein in the pentylenetetrazol-kindled rats. Brain Res 1238: 108-117, 2008.

48. Zha XM, Dailey ME and Green SH: Role of Ca2+/calmodulin-dependent protein kinase II in dendritic spine remodeling during epileptiform activity in vitro. J Neurosci Res 87: 1969-1979, 2009. 